\title{
Salinity: Translating information from model microbes into crop plants
}

\author{
Naveen K. Sharma ${ }^{\mathrm{a}}$, Meenakshi Singh ${ }^{\mathrm{b}}$, Ashwani K. Rai ${ }^{\mathrm{b}, *}$ \\ ${ }^{a}$ Department of Botany, Indira Gandhi National Tribal University, Amarkantak (MP) 484887 India \\ b Department of Botany, Banaras Hindu University, Varanasi 221005 India
}

*Corresponding author, e-mail: akrai@bhu.ac.in

Received 29 Jan 2021

Accepted $23 \mathrm{Feb} 2021$

\begin{abstract}
Because of the gradual increase in soil salinity worldwide, the study of halophiles nowadays is an important emergent discipline. High salinity limits the microbe's diversity, community structure and their metabolic activities, consequently reducing the soil fertility. This leads to decreased crop yield that presents a grave and global socioeconomic problem. Crop plants are relatively more sensitive, and their growth inhibition and reduction in the yield usually occur at salinity of $50 \mathrm{mM}$ or above. Halophilic and halotolerant organisms that live and acclimate/adopt to high salinity environments have various strategies to survive, protect their proteins and other cellular processes to grow in the challenging environment. They possess efficient mechanisms to sense the stress signals by, for instance, signal transducing systems, alteration of the composition of the membranes, exclusion of $\mathrm{Na}^{+}$and prevention of $\mathrm{K}^{+}$leakage from the cells, and synthesis of organic solutes. In this article, we also discuss the responses of these organisms such as alteration in photosynthesis and respiration, nitrogen nutrition, reactive oxygen generation and programmed cell death, and adjustment and/or adaptation to salt stress, along with the exploration of efforts like salt priming and memory, and genetic engineering for developing salt tolerant crop plants.
\end{abstract}

KEYWORDS: cyanobacteria, halophile, reactive oxygen species, salt priming

\section{INTRODUCTION}

Salt is vital for life on the planet. The societal value of salt has always been recognized by different cultures. For instance, Homer described salt as a "divine substance" and Plato wrote of its value to the Gods. Salt is required not only by humans, but the entire flora and fauna of the planet including microorganisms. However, the regulation of the salt concentration of cells and their habitats is a key; the abundance or absence of salt can lead to cellular and environmental imbalances with potentially fatal consequences to the organism. Excess concentration of salts in soils is implicated as a principal cause of historic and modern agricultural productivity losses $[1,2]$. It was possibly the first environmental hazard, which resulted from water logging and long period of irrigation without adequate drainage. It is believed that salinity that resulted from 1000 to 1500 years of agriculture had led to the decline of the Sumerian civilization in Mesopotamia (modern Iraq). By 1700 BC, wheat (a salt sensitive staple crop) completely disappeared from the Mesopotamia and was replaced by more salt tolerant barley $[1,3]$. Similar problems had been reported from the Indus-Plain (Harappa Civilization, that includes parts of modern-day India and Pakistan) [4], Viru Valley on the coast of Peru [5] and Salt River region in modern Arizona, USA, once inhabited by Hohokam Indians [6].

In general, salt-affected soils are those having high levels of water-soluble mineral salts such as $\mathrm{CO}_{3}^{2-}, \mathrm{Cl}^{-}, \mathrm{SO}_{4}^{2-}$ and $\mathrm{HCO}_{3}^{-}$of $\mathrm{Ca}^{2+}, \mathrm{Mg}^{2+}$, and $\mathrm{Na}^{+}$. However, most of the saline research centers around $\mathrm{NaCl}$ salinity because $\mathrm{Na}^{+}$is the dominant cation and $\mathrm{Cl}^{-}$the anion in the majority of saline soil. Worldwide, approximately 930 million ha of land ( $>$ $7 \%$ of arable land) are estimated to be salt affected, out of which about 95 million hectares are under primary salinization (high amounts of inherent salts from sources such as rock weathering [7]). Secondary salinization caused by irrigation with saline or poor water quality without sufficient leaching of salt, high evaporation rate, and other anthropogenic land-use practices is another major problem (Fig. 1), which is increasing at an alarming rate. Approximately 4 million hectares of global agriculture land is abandoned annually due to excessive salt [8]. Hence, the major problem is the secondary salinization - once cultivable land going out as salt 


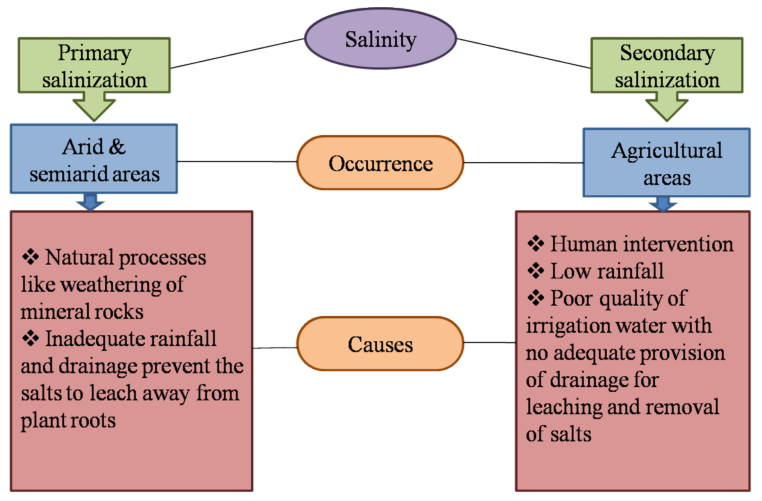

Fig. 1 Types of soil-salinization. Based on the source of origin, salinization could be primary occurring mainly through natural processes like weathering of rocks and soils, and secondary arising due to human intervention.

affected wastelands. Salinity not only adversely affects crop productivity and quality worldwide, it negatively affects soil physico-chemical properties, and has a detrimental effect on microbial diversity, their community structure, biomass and activity, consequently soil productivity [9].

A fine regulation of cellular salt concentration to that with the external medium is essential for the continuity of life. Salinity reduces growth through changing water and ionic status of the cells. High salt concentration causes reduced water uptake with concomitant decrease in micronutrients availability to the cells. It also produces hyperosmotic stress (ionic imbalance and chaotropic effects) due to the turgor imbalance, and other secondary stresses such as nutritional disorder and oxidative stress [10]. Chaotropic solutes weaken the electrostatic interactions of the constituting molecules, which destabilize the biological macromolecules. Contrary to this, kosmotropes (e.g., majority of compatible solutes) strengthen the electrostatic interaction, thus stabilize the macromolecules and protect cells from the osmotic stress [11].

Salt-rich (e.g., saline/haline and hypersaline) environments contain plethora of microbes [12]. They are either halotolerant (i.e., prefer the ambient environment but are able to survive and grow in high-salt environments) or halophilic (i.e., saltloving, essentially require a certain concentration of salt to attain optimal growth in nature). Both forms have been reported from saline and hypersaline lakes, coastal dunes, saline deserts, salt marshes, and inland salt seas and springs [12]. Depending upon their ability to withstand salt concentration,
Table 1 Examples of extreme halophiles and their habitats.

\begin{tabular}{|c|c|c|}
\hline Group & Name & Habitat \\
\hline \multirow[t]{6}{*}{ Archaea } & Halobacterium sp. NRC-1 & $\begin{array}{l}\text { The Great Salt Lake } \\
\text { in Utah, USA, salin- } \\
\text { ity almost similar to } \\
\text { seawater }\end{array}$ \\
\hline & Haloarcula marismortui & Dead Sea, Israel \\
\hline & Haloferax volcanii & Dead Sea, Israel \\
\hline & Halorubrum lacusprofundii & Dead Sea, Israel \\
\hline & Natronomas pharaonis & $\begin{array}{l}\text { Lake Magadi, } \\
\text { Kenya }\end{array}$ \\
\hline & Salinibacter ruber & $\begin{array}{l}\text { Solar salterns, } \\
\text { Spain }\end{array}$ \\
\hline Bacteria & Halobacillus halophilus & Salt marsh soil \\
\hline \multirow[t]{2}{*}{ Cyanobacteria } & Synechococcus & Relatively low salt \\
\hline & Aphanothece halophytica & Dead Sea, Israel \\
\hline Microalgae & Dunaliella salina & Salt ponds \\
\hline
\end{tabular}

halophiles are categorized as: low $(<1.5 \mathrm{M})$, moderate (1.5-3.0 M) and extreme halophiles [ $>3.5 \mathrm{M}$ - to salt saturation point; for $\mathrm{NaCl}$ the saturation level is $300 \mathrm{~g} / \mathrm{l}$ (i.e., $5 \mathrm{M}$ )]. Table 1 contains examples of some of the extreme halophilic microbes and characteristics of their respective habitats.

Halophilic microbes are distributed in all the three domains of life - archaea, bacteria and eukarya. Prokaryotes constitute the bulk of the highsalt microflora, while archaea dominating at extremely high salt concentration [13]. Nature has provided these microbes with an impressive array of unusual, but efficient and highly regulated mechanisms to combat the challenges presented by extreme salinities, and these mechanisms are deliberated in the following sections. We shall discuss the mechanisms adopted by these organisms: (i) mainly against the $\mathrm{NaCl}$ stress, which is the most common salt in hypersaline environments; (ii) with an aim to exploit relevant information on their ecology for the ongoing efforts on engineering salt tolerant crop plants. Our discussion will primarily focus around cyanobacteria, an ancient group of phototrophic bacteria showing plant like photosynthesis (oxygenevolving); with a priori that they are an appropriate microbial model/counterpart for higher plants [14]. Wherever needed, appropriate information from other microbes will also be presented. 
Table 2 The upper salt limit at which various microbial metabolic processes occur (adopted from [12]).

\begin{tabular}{|c|c|}
\hline Salt concentration & Metabolic processes \\
\hline $\begin{array}{l}300 \mathrm{~g} / 1 \\
\text { (salt-saturation level) }\end{array}$ & $\begin{array}{l}\text { Oxygenic and anoxygenic photosynthesis, } \\
\text { aerobic respiration and denitrification }\end{array}$ \\
\hline$>200 \mathrm{~g} / 1$ & $\begin{array}{l}\text { Fermentation, aerobic autotrophic oxi- } \\
\text { dation of sulfur compounds, sulfate re- } \\
\text { duction by incomplete oxidation (lactate } \\
\rightarrow \text { acetate), methanogenesis from methy- } \\
\text { lated amines, homoacetogenesis (acetate } \\
\leftarrow \mathrm{CO}_{2}+\mathrm{H}_{2} \text { ). However, these processes } \\
\text { either do not or function poorly in salt- } \\
\text { saturated environments. }\end{array}$ \\
\hline $100-200 \mathrm{~g} / 1$ & $\begin{array}{l}\text { Processes such as autotrophic oxidation } \\
\text { of ammonia and nitrite, methanogenesis } \\
\text { by reduction of } \mathrm{CO}_{2} \text { with } \mathrm{H}_{2} \text { as electron } \\
\text { donor, methanogenesis from acetate, sul- } \\
\text { fate reduction with acetate as electron } \\
\text { donor are limited to salt concentration }\end{array}$ \\
\hline
\end{tabular}

\section{SALT INDUCED CONSTRAINTS TO LIFE}

\section{Energetic constraints}

Life becomes energetically expensive at high salinity. Organisms inhabiting high salt environments require additional energy to grow and survive. The mode of adaptation (refer following sections) used, and amount of energy generated during dissimilatory metabolism determine the existence of life at high salt concentrations [12]. Availability of metabolic energy delineates the upper salt concentration at which different dissimilatory processes can take place. Phototrophic microbes using light as energy source has an additional energy-generating pathway, the photosynthesis. This is an exergonic process producing high amount of ATP (cf. aerobic respiration, denitrification, etc.), hence such organisms are better adapted to salt life compared to that of heterotrophs [12]. A detailed account of energetic constraints experienced by microbes at high salinity, as well as the maximal salt concentrations at which vital metabolic processes could operate is presented (Table 2).

\section{Stability of proteins}

Salt interferes with the ordered structure of water bound molecule, increasing the randomness or entropy of the system with decrease in the water potential. The chemical potential is largely dependent on the change in the entropy of the water. The equation for chemical potential of water is given by:

$$
\Delta \mu_{\mathrm{w}}=\Delta H_{\mathrm{w}}-T \Delta S_{\mathrm{w}}
$$

where $\Delta \mu_{\mathrm{w}}$ is change in the chemical potential of water, $\Delta H_{\mathrm{w}}$ is the change in enthalpy of the reaction, $\Delta S_{\mathrm{w}}$ signifies change in entropy and $T$ denotes temperature in Kelvin. Gibb's free energy of unfolding and enthalpy change increases with an increase in the concentration of osmolytes (such as betaine, sarcosine, proline and sucrose), while decreases sharply when treated with denaturants like urea and guanidine chloride [15]. Normally, during stress, hydrophobic surfaces are exposed leading to the aggregation of the proteins and ultimately the cell death [16].

In general, isoelectric points (pI) of nonhalophilic proteomes lie close to basic (pI 10) and acidic (pI 5) points, whereas proteomes of halophiles have significantly low pI. Acidic amino acids protect the proteins from high ionic molecules and get stabilized by cooperative interaction of acidic surface residues with hydrated solvent ions. Furthermore, proteins of halophiles exhibit low water activity and strong salting out effects with high surface negative charge [17], with a tendency to bind salts. This decrease in salt content eventually unfolds the protein.

There are two distinct cytoplasmic water populations of different physical properties: (a) dense or weakly bonded water in the hydration shell of proteins and (b) less dense water (or structured water) in bulk [18]. The hydration water is a changeable shell of water surrounding the protein and depends upon the degree of attraction to the protein. It is thermodynamically very different from bulk water and is important for maintaining the 3-D structure and activity of proteins. Different solutes show preferences for one or the other water populations. Small and highly charged molecules prefer to dissolve in hydration water, while large molecules of low charge density favor bulk water. Because of their strongly bonded hydration shell, compatible solutes fit better into the structured form of water. Resultantly, they are excluded from the hydration shell of proteins due to their preference for less dense water (i.e., preferential exclusion model). The protective effect of compatible solutes is the consequence of surface minimization.

\section{Membrane fluidity}

Salt-stress causes shortening of fatty acid chains and desaturation of membrane lipids. A relationship between fatty acid unsaturation and salinity tolerance was revealed using the Synechocystis sp. PCC 6803 mutant cells $\operatorname{des} A^{-} / \operatorname{des} D^{-}$, inactivated for D12 and D6 desaturases, respectively [19]. In an increased $\mathrm{NaCl}$ concentration, des$A^{-} /$des $D^{-}$cells showed a complete loss of $\mathrm{Na}^{+} / \mathrm{H}^{+}$antiport system, 
while the wild type cells could show approximately half of the original activity. A rapid inactivation of PSII in $\operatorname{des} A^{-} / \operatorname{des} D^{-}$cells compared to that of wild cells was also evident [19]. In contrast, $\operatorname{des} A^{+}$ cells (Synechococcus cells transformed with $\operatorname{des} A$ gene from Synechocystis sp. PCC 6803) exhibited increased synthesis of unsaturated fatty acids (16:2 fatty acids), and were more resistant to salt stress than that of the wild type [20]. Furthermore, high salt concentration in the incubation medium inactivated the PSII of both the wild type and $\operatorname{des} \mathrm{A}^{+}$ Synechococcus cells, but was slower in the later. However, the presence of light restored the PSII activity relatively faster and efficiently in $\operatorname{des} A^{+}$cells than that of the wild type [20].

\section{ACCLIMATIZATION AND ADAPTATIONS TO THE SALT STRESS}

\section{Sensing the change in external salt concentration}

Sensing the change in the ambient concentration of salt is the first and a crucial step to salt adaptation. Halophiles possess specific system(s)/mechanism(s) to sense the high osmolarity of the external medium. In cyanobacteria, the sensing system (of sensor-transducer system) is composed of two components: (i) serine/threonine protein kinases (spks) and (ii) sigma factors of RNA polymerase [21]. Nearly 44 Hiks (histidine kinases) putative chromosomal and three plasmid coded genes have been reported in cyanobacterium Synechocystis [22]. Inactivation of Hik genes (Hik16, Hik33, Hik34, and Hik41) have confirmed their role in sensing of salt signals. These genes regulate different sets of genes involved in salt stress, which account to almost $20 \%$ of the salt inducible genes. Amongst these, Hik16 and Hik41 have shown response only to $\mathrm{NaCl}$, while Hik33 has responded to Na salts. The screening of the hik (i.e., hik20, hik27, and hik34 genes) mutant library of cyanobacterium Synechocystis suggested that some genes are negatively regulated (e.g., $\Delta$ hik16 (slr1805), $\Delta h i k 33$ (sll0698), $\Delta$ hik34 (slr1285), and $\Delta$ hik41 (sll1229) by salt. Their expression level in the mutant cells reduced with an increase in the $\mathrm{NaCl}$ concentration [23]. A total of 5 Hik-Rre systems, namely, Hik33-Rre31, Hik10-Rre3, Hik16-Hik41Rre17, Hik2-Rre1, and Hik34-Rre1, were found to be involved in salt sensing and subsequent transduction of the signal [24].

A genome wide transcriptional analysis of Synechocystis has revealed that hyperosmotic stress- inducible genes are mainly induced by Hik33 [25]. This gene is involved in the synthesis and maintenance of the cell wall and membranes, formation of a phosphate-transport system, and in the protection of the photosynthetic apparatus. It was anticipated that Hik33 recognizes signals of hyperosmotic stress through changes in membrane fluidity [26].

Calcium is known to play a pivotal role in salt stress signaling. Its intracellular concentration increases on increasing the salinity and osmotic stress [27]. Moreover, $\mathrm{Ca}^{2+}$ influx increases with an increase in extracellular $\mathrm{Ca}^{2+}$ concentration. A marked reduction in intracellular calcium level has been observed after treatment with EGTA (a calcium chelator) and verapamil (a $\mathrm{Ca}^{2+}$ channel blocker), suggesting the involvement of verapamil sensitive channels in calcium influx.

\section{Strategies adapted by microbes at high salt concentrations}

Due to loss of water, salt induced osmotic upshift causes decrease in the turgor pressure of exposed cells that results in shrinkage of the cell membrane. In order to maintain the osmotic balance, microbes such as Halanaerobiales (halophilic anaerobic bacteria) and Halobacteriales (Archaea) accumulate high amount of $\mathrm{K}^{+}$inside the cells ('salt in' strategy), provided the high concentration of $\mathrm{KCl}$ in the external medium. These microbes possess highly acidic proteome, with majority of proteins functioning only in the presence of salt [12]. A combined action of the membrane bound bacteriorhodopsin, ATP synthase and $\mathrm{Na}^{+} / \mathrm{H}^{+}$antiporter generates electric potential in Halobacteriales driving the uptake of $\mathrm{K}^{+}$. Pigments such as $\beta$-carotene [28], bacteriorhodopsin and halorhodopsin (produced by Halobacterium) protect organisms against high salinity. Bacteriorhodopsin uses sunlight to drive proton pumps leading to transmembrane proton gradient formation [29].

Based on the observation that moderately halophilic bacterium Halobacillus halophiles grows well in $\mathrm{NaCl}$, but not in $\mathrm{Na}_{2} \mathrm{SO}_{4}$, it is argued that chloride ions play an important role in counterbalancing the high salinity [30]. Chloride ion is taken up via primary or secondary transporters [31]. For example, a light driven halorhodopsin (chloride pump) that consists of membrane protein halorhodopsin bound to the lysine residue (Lys ${ }^{242}$, acting as Schiff base) is suggested to be involved in the transport of $\mathrm{Cl}^{-}$. Lysine and other amino acids act as an active site of the chloride pump, which absorbs light of $578 \mathrm{~nm}$ wavelength. Absorption 
of one photon causes activation of photochemical reaction leading to the transport of one molecule of $\mathrm{Cl}^{-}$from the external medium. High external $\mathrm{Cl}^{-}$ concentration leads to an increase in the cellular $\mathrm{Cl}^{-}$ level till a steady state of $0.5-0.8 \mathrm{M}$ is attained [32]. At low external $\mathrm{Cl}^{-}$concentration, $\mathrm{Cl}^{-}$is largely excluded from the cytoplasm.

At high salt concentrations many of the microbes exclude $\mathrm{Na}^{+}$ion from their cells either via $\mathrm{Na}^{+} / \mathrm{H}^{+}$antiporters operating through transmembrane proton gradient [10] or via ATP-driven $\mathrm{Na}^{+}$-pumps located in the plasma membrane (P-type $\mathrm{Na}^{+}$-ATPase) [33]. Different plasma membrane bound ATPases such as $\mathrm{Na}^{+} / \mathrm{K}^{+}$-ATPase (in animal cells) and proton-dependent $\mathrm{H}^{+}$-ATPase (in plants and fungi) help in maintaining concentration gradients as well as regulate cellular homeostasis [34]. In addition to $\mathrm{H}^{+}$-ATP synthase, a putative $\mathrm{F}_{1} \mathrm{~F}_{0}$ - type $\mathrm{Na}^{+}$-ATP synthase $\left(\mathrm{ApNa}^{+}\right.$-ATPase) operon $\left(\mathrm{ApNa}^{+}\right.$atp) has been reported in halophilic cyanobacterium Aphanothece halophytica [35], and have been successfully overexpressed in a freshwater cyanobacterium to enhance its salt tolerance [36].

Alternatively, as a measure to overcome the salt stress, halophilic microbes synthesize de novo or accumulate organic compatible solutes (osmolytes and osmoprotectants) from the external medium, if available. These are low molecular weight uncharged organic solutes and include glycerols (polyols), sucrose and trehalose (sugars), glycine betaine (hereafter referred to as GB), ectoine, $\mathrm{N}$-acetylated diamino acids and N-derivative carboxamides of glutamine (amino acid derivatives). They have no adverse effect on enzymic activity of the organisms. To maintain osmotic equilibrium, the molar concentration of the intracellular solutes should equal the ionic concentration of the surrounding medium. Theoretically, cells growing in $1 \mathrm{M} \mathrm{NaCl}$ should contain $2 \mathrm{M}$ of an electrically neutral solute. However, the actual values reported are low [12].

The level of salinity that could be tolerated by any organism is linked to the class of organic solute they synthesize and accumulate. In general, freshwater and marine strains of cyanobacteria synthesize carbohydrates such as sucrose and trehalose as major organic solutes [37]. The intermediate halotolerant forms synthesize heteroside glucosyl glycerol. Whereas, the quaternary ammonium compounds GB and glutamate betaine are synthesized and/or accumulated by halotolerant and halophilic cyanobacteria from hypersaline environments [38]. Certain forms also accumulate additional organic solutes depending upon growth temperature, ambi- ent salinity and duration of salt stress. A detailed account on the ways metabolic engineering could be used to enhance accumulation of osmoprotectants in plants has been presented [39].

Infrared spectroscopic analyses revealed that compatible solutes form strong water-structure and as such are excluded from the hydration shell of proteins. This "preferential exclusion" explains their function as effective stabilizers of the hydration shell of native proteins. These solutes thus help in maintaining native (i.e., folded) protein structures in thermodynamically favored state, presenting the least possible surface area to the water. Many ionic solutes such as $\mathrm{NaCl}$ or $\mathrm{MgSO}_{4}$ interact directly with protein surfaces, causing unfolding and denaturation of the protein. With an increase in the turgor pressure, the mechano-sensitive channels in the membranes are activated to excrete the extra osmolytes. For example, MscL (mechano-sensitive channel of large conductance), a protein helps in sensing hypo-osmotic stress. It exports the solutes non-selectively from cells during hypo-osmotic stress [40], thus regulating cell volume.

The choice of strategy to be adopted by the organisms depends upon energetic cost of the process [12]. The energetic cost of 'salt in' strategy is low compared to that of salt exclusion and compatible salt synthesis/accumulation. Likewise, the energetic cost of de novo synthesis of compatible solutes is higher compared to that of accumulating from the external medium.

\section{PHYSIOLOGICAL AND BIOCHEMICAL RESPONSES OF PHOTOAUTOTROPHS TO HIGH SALINITY}

\section{Photosynthesis and respiration}

Sodium plays an important role in photosynthesis, but excess of $\mathrm{Na}^{+}$during salinity stress causes deleterious effect $[41,42] . \mathrm{Na}^{+}$-deficiency and hyperaccumulation both causes loss of photosynthetic pigments and severe inhibition of oxygen evolution. Cyanobacterial photosynthetic process is similar to that of higher plants except that the cyanobacterial thylakoid membranes are the only sites for both the photosynthetic and respiratory electron transport. Salinity negatively affects the growth, chlorophyll content [43], carbon fixation and RuBisCO activity [44]. Phycobiliproteins, light harvesting complex in cyanobacteria are also sensitive to salinity. Carotenoid content increases under salt stress and affords protection to chlorophyll due to absorption of photons. The damage caused by osmotic stress is 
reversible, while irreversible in case of ionic stress [20]. The main target of salt stress appears to be PSII reaction center. and its D1 protein $(34 \mathrm{kDa})$ [42], which become more apparent when the salt treated cells are exposed to PAR (photosynthetically active radiation) but not in the dark [45]. Salt stress is reported to inhibit the repair of photodamaged PSII [20]. Moderate salinity while reduces the whole chain and PSII electron chain activity, increases the PSI activity and tends to increase PSI/PSII ratio [46]. This is due to the disrupted linkage between PSII and I reaction centers, resulting in reduced electron transport from PSII to PSI, and added excitation of oxidized PSI and increased PSI electron transport activity [46]. An increase in the amount of P700 and PSI reaction center [47], under salt stress has been noted in Ap. halophytica, consequently increased cyclic electron transport from PSI. However, the change in PSI electron transport activity is reportedly faster than P700 content adjustment [41].

Along with the PSI activity, salinity increased the activity of complex IV (ATP synthase) too, which suggested that PSI reaction center as well as the components other than cytochrome c oxidase are involved. The enhanced ATP synthase activity can be attributed to an over demand of ATP under salt stress to increase the active extrusion of $\mathrm{Na}^{+}$and restoration of cellular homeostasis [48]. Salt stress also affects the dark reaction of photosynthesis and carbon assimilation [49]. Unsaturation of fatty acid chains in the membrane and compatible solutes such as GB increase the salt tolerance and protect the metabolic machineries of the photosynthetic organisms $[20,46,50]$.

Under salt stress, rate of respiration increases [41]. Marine cyanobacterium Spirulina subsalsa when transferred from saline to hypersaline medium showed enhanced respiration [51]. That is due to the reduced photosynthesis combined with the high-energy demand of salt-affected cells. Thus, the enhanced respiration was to compensate the reduced level of photosynthesis under salt-stressed cells, and possibly to curtail influx and enhance the efflux of $\mathrm{Na}^{+}$ions $[46,48]$.

\section{Nitrogen metabolism}

Nitrogen is the most limiting macronutrient and is often required in high amount for the growth of plants and microorganisms, yet a little and fragmentary information is available on the effect of salt stress on nitrogen metabolism. In cyanobacteria, high salinity causes shortening of the cyanobacterial filaments and reduction in heterocyst frequency resulting in reduced $\mathrm{N}_{2}$-fixation [43]. Though $\mathrm{Na}^{+}$is required at a low concentration $(25 \mu \mathrm{M})$ for the nitrogenase activity, higher concentrations are equally toxic [52]. Furthermore, $\mathrm{NaCl}$ is noted to interfere with the assemblage of the nitrogenase complex by binding to the Fe protein [53]. Apart from the direct effect, the inhibition of nitrogenase activity by $\mathrm{NaCl}$ stress is also indirect due to the inadequate supply of photosynthetically generated ATP and reductants [52] and poor protection of the nitrogenase from oxygen inactivation due to altered membrane permeability of heterocyst [54]. The Anabaena doliolum cells transformed with $\mathrm{N}$-methyltransferase genes synthesized and accumulated GB, and showed increased salt tolerance and protection to nitrogenase activity [55]. It is worth mentioning that both the processes, methylation of glycine and nitrogen fixation are energetically costly processes that need methyl donor S-adenosylmethionine (SAM) for the biosynthesis of dinitrogenase active site FeMo-Co as well as GB. The diversion of SAM towards GB synthesis could be detrimental for nitrogenase maturation [55]. Out of various compatible solutes tried [38], GB was the most effective in protecting glutamine synthetase activity of freshwater, marine and salt tolerant cyanobacteria against salt toxicity.

Exogenous supplementation of nitrate $(5 \mathrm{mM})$ protected $A$. doliolum cells against the adverse effect of salt stress [56], but only at sub-lethal $\mathrm{NaCl}$ concentration $(<300 \mathrm{mM})$. Nitrate in the saline medium interacted with the $\mathrm{Na}^{+}$carrier and reduced the uptake of $\mathrm{Na}^{+}[52,57]$. The mutant of Anabaena sp. PCC 7120, defective in nitrate uptake exhibited the lowest level of cellular sodium affirms the view that $\mathrm{Na}^{+}$and $\mathrm{NO}_{3}^{-}$enter the cell in a symport manner. Despite the lowest cellular sodium content, the mutant cells were as sensitive to salt toxicity as the wild type. This denotes that the presence of a toxic level of $\mathrm{NaCl}$ in the growth medium is sufficient to alter the structural and/or functional components of the plasma membrane by enhancing the surface charge responsible for the modification of ion exchange properties, increasing membrane fluidity, reducing permeability of $\mathrm{H}^{+}$and $\mathrm{Na}^{+}$, respiratory activity associated with the plasma membrane, interaction with the Pi transporter, and inhibiting phosphate uptake resulting in limited ATP supply [52,57]. Nitrate assimilation in general, and especially in cyanobacteria is directly linked to photosynthesis. In cyanobacteria, both nitrate and nitrite reductases are ferredoxin-dependent; hence through consuming the excess photosynthetic 
electrons minimize the adverse salt-effects on photosynthesis and act as an alternative sink for the photosynthetic electrons and lessen the adverse salteffects on photosynthesis $[46,58]$.

\section{Phosphorus metabolism}

Autotrophic microbes avail phosphorous (P) mainly in the inorganic orthophosphate forms, $\mathrm{H}_{2} \mathrm{PO}_{4}^{-}$and $\mathrm{HPO}_{4}^{2-}$, though, certain microbes can also utilize phosphonates, phosphite and hypophosphite forms [59]. Salinity reduced the intracellular phosphate level and phosphate uptake rate in freshwater cyanobacterium A. doliolum, [60]. As observed in A. doliolum, the cellular $\mathrm{P}$ level in halophilic Ap. halophytica cells also decreased under salt stress [61]. Further, the total APase (alkaline phosphatase activity) in A. doliolum cells increased under salt stress, registering 7-folds increase in extracellular activity with 3 -folds decrease in cell-bound activity [60]. In Ap. halophytica, phoD gene responsible for the $\mathrm{Ca}^{2+}$-dependent APase and phosphodiesterase (APDase) activities was upregulated by P-starvation and under salt stress. However, the activity was much higher under salt stress than that of P-starvation [61]. The upregulation of $p h o D_{A p}$ under salt stress could promote the utilization of extracellular organic compounds as a P source. The halophilic cyanobacterium Ap. halophytica showed luxuriant growth at $\mathrm{P}$ concentration lethal for freshwater forms, and adopt various strategies for the conserved use of $\mathrm{P}$ [62].

\section{Reactive oxygen species (ROS), oxidative stress and programmed cell death (PCD)}

Since $\mathrm{O}_{2}$ has a tendency to undergo univalent reductions, generation of ROS such as reactive singlet oxygen $\left({ }^{1} \mathrm{O}_{2}\right)$, superoxide anion $\left({ }^{\bullet} \mathrm{O}_{2}^{-}\right)$, hydrogen peroxide $\left(\mathrm{H}_{2} \mathrm{O}_{2}\right)$, hydroxyl radical $\left(\mathrm{OH}^{\bullet}\right)$ and perhydroxyl radical $\left(\mathrm{O}_{2} \mathrm{H}^{\bullet}\right)$ is obvious during normal aerobic metabolism. Environmental factors including salinity could lead to increased ROS production causing an oxidative stress. Salinity induced ROS generation is primarily due to the impaired photosynthetic and respiratory activities resulting in increased electron production and limited electron acceptors. The excess electrons then reduce $\mathrm{O}_{2}$ to form ROS. Furthermore, salt stress increases the rate of respiration that results in overreduction of the ubiquinone pool causing leakage of electrons from complex I and III to $\mathrm{O}_{2}$ generating ROS [63]. However, phototrophs have enzymic and nonenzymic antioxidants to scavenge the ROS. When this balance of oxidant levels (ROS) and antioxidant production is lost, the organisms have to face an oxidative stress that harms the cells in various ways ranging from, for example, cell death in prokaryotes to serious pathologies in higher organisms. Evidence of salinity induced in vivo biphasic ROS accumulation evoking oxidative stress in the cyanobacterium Anabaena fertilissima has been provided for the first time [64]. The fist burst of ROS (intense and short-lived) was recorded immediately of salt exposure, followed by the second (of low magnitude and long-lived) at $4 \mathrm{~h}$ of salt stress. Plasma membrane NADPH oxidases and cell wall peroxidases [65] are argued to be responsible for the early phase ROS generation, while altered photosynthetic and respiratory parameters for the phase II ROS generation [64]. In Arabidopsis, ROS produced by NADPH oxidases during salt stress is reported to act as a signal molecule to regulate ion homeostasis [66]. The phase II ROS generation, for its low magnitude was credited to the rapid activation of robust antioxidative systems in cyanobacteria [64]. It is worth mentioning that cyanobacteria are responsible for the oxygenation of the planet Earth, hence the first organisms to be challenged with oxygen and its byproduct ROS, thus must be evolved to possess robust antioxidative systems. For instance, cyanobacteria contain flavodiiron proteins (Flv1 and Flv3) that perform a unique Mehler reaction (light-mediated alternative electron transport to $\mathrm{O}_{2}$; water-water cycle), reducing $\mathrm{O}_{2}$ to water without generating ROS, which is fast with high capacity [67], capable to provide immediate protection to stressed cyanobacterium. The proteins are found in all photosynthetic organisms (from cyanobacteria to gymnosperms), but absent in angiosperms [67].

Some recent reports [68] show that moderate level ROS can activate apoptotic-like PCD to remove the damaged cells [69]. Ecophysiologically, death of the suicidal cell in cyanobacteria is crucial to the developmental processes like differentiation of heterocysts, filament polarity and hormogonia formation for dispersal of the cells and false branching $[70,71]$.

\section{SALT STRESS PRIMING AND MEMORY}

Acclimation refers to the response (adjustment) of an organism to its environment that occurs in a short period, and within the organism's lifetime (compared to adaptation), and has been studied in detail in cyanobacteria. On the other hand, adaptation is a long-term process, and is kept as a generic term and is usually defined as the ability to survive, function 
and reproduce; the process of change that makes an organism better equipped to its habitat. Stress priming and memory, an adaptive strategy is the exciting and growing field of research. Researches in recent years have shown that plants can recollect their past stress and prime the responses to react fast and strongly to bigger stress.

For salt priming/adaptation, A. fertilissima cells growing at $100 \mathrm{mM} \mathrm{NaCl}$ for a week were given a stepwise increase of $50 \mathrm{mM} \mathrm{NaCl}$ (in the nutrient solution) every week, until the $\mathrm{NaCl}$ level reached $500 \mathrm{mM}$. The cells were routinely cultured in the growth medium supplemented with $500 \mathrm{mM} \mathrm{NaCl}$ [72]. Salinity beyond $100 \mathrm{mM} \mathrm{NaCl}$ was inhibitory to the growth of the parent cyanobacterium and was lethal at $500 \mathrm{mM}$, whereas the salt-primed (adapted) cells grew luxuriantly and competently at $500 \mathrm{mM} \mathrm{NaCl}$, similar to the parent cells growing in non-saline nutrient solution. Salinity impaired the photosynthetic activities, increased the respiration rate and antioxidant activities in parent cells, but not in the salt-primed cells, except a marginal increase in PSI activity. Salinity increased the uptake of intracellular $\mathrm{Na}^{+}$and $\mathrm{Ca}^{2+}$ and leakage of $\mathrm{K}^{+}$in parent cells, while cation levels in salt-adapted cells were comparable to control [72]. This might be one of the reasons for the usual metabolic activities and copious growth of adapted cells under salinity.

Proteome kinetic analysis revealed that salinity altered the protein abundance and increased the expression of the four identified proteins of A. fertilissima (showing close homology with photosystem I reaction center subunit XII, epoxyqueuosine reductase, response regulator protein VraR and molybdopterin biosynthesis protein). However, minimal hyper accumulation of these proteins was noted in salt-adapted cells exposed to $500 \mathrm{mM} \mathrm{NaCl}$ concentration [73]. The Azolla-Anabaena system primed to mild salt stress for a specific time period could tolerate and grow at otherwise lethal $\mathrm{NaCl}$ concentration [74]. This showed that the organism pre-exposed to mild and stepwise salt stress underwent priming effect, an adaptive strategy in such a way to perform normal photosynthesis, which enabled them to respire normally and face the least stress allowing them to conserve energy for growth and essential physiological processes. The priming stimuli salinity transmitted warning signals to the cellular machinery, which induced physiological, transcriptional, metabolic, and epigenetic changes in organisms [75]. Environmental stress could influence the epigenetic processes and generate particular defense changes to adapt to extreme fluctuations in environmental conditions such as salinity across generations [76]. The technique, salt-priming appeared a simple and preferred way to develop salt tolerant cyanobacterium to improve the nitrogen status of the saline fields. Salt-priming of crop plants (seeds) could be an easy and favored technique for developing salt tolerance in crops, which needs exploration.

\section{SALT TOLERANT PLANTS FOR SUSTAINABLE AGRICULTURE}

Salt stress is one of the major abiotic stresses negatively affecting photosynthesis, growth and development of plants. An understanding of the saltstress-tolerance mechanisms in plants is key to salttolerant crop improvement programs. There are two ways to strengthen global food security: (i) to bring new areas under agriculture and (ii) to develop crop varieties that can grow in stressful environment especially, saline environments. However, due to rising demand for housing and other human activities, increase in global arable land area is likely to have limited success.

To survive high salinity conditions, plants fundamentally rely upon morphological, developmental, biochemical and physiological modifications. At molecular level, plants respond at transcriptomic and post-transcriptomic levels. Several genes and transcripts are involved in these adaptive processes. By specifically targeting and regulating transcripts, miRNAs may contribute to abiotic tolerance. Besides, several other strategies have been developed to improve salt-tolerant cultivars.

The recent advances in horizontal gene transfer technology have enabled scientists to introduce new and potent genes from other sources into crop plants. Thus, offering a great potential to improve crop plants against various stresses. One initial way was the use of Agrobacterium-mediated transgene transfer that got integrated at random positions in the target plants genome. Subsequent advancement in direct DNA transfer techniques (particle bombardment, electroporation, chemical treatment, etc.) has opened new ways and made things a little bit easier. However, we still lack efficient gene transfer methods for many crops. The major components involved in the development of transgenic plants are: the development of reliable tissue culture regeneration systems (1), preparation of gene constructs and transformation with suitable vectors (2), appropriate transformation techniques for the introduction of the gene into crop plants (3), recovery and multiplication of transgenic plants 


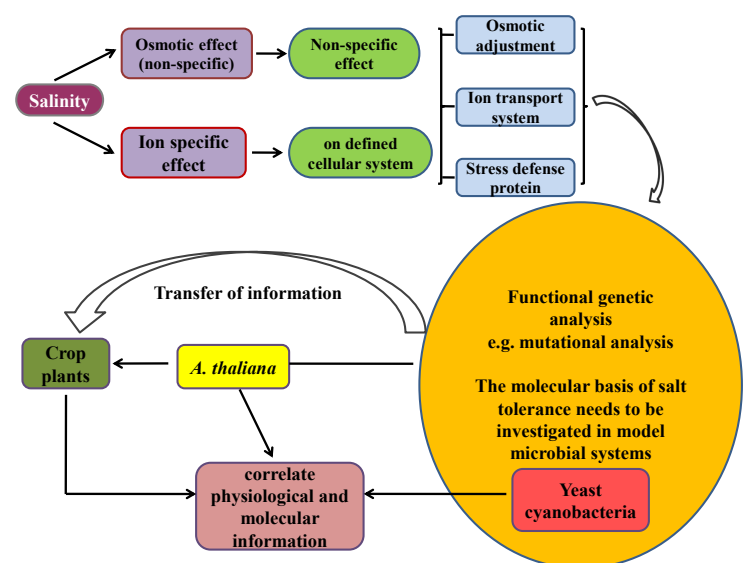

Fig. 2 A schematic representation of the flow of information from microbes to crop plants.

(4), molecular and genetic characterization of transgenic plants for stable and efficient gene expression (5), if needed, transfer of genes into cultivars by conventional breeding methods (6), evaluation of transgenic plants for their effectiveness in withstanding the biotic and abiotic stresses without being an environmental hazard (7) (see [77] for detail). However, each step has its own limitations.

Possible exploitation of information emerging from halophilic microbes could help us in tackling this problem. To achieve this, there is a need to unmask the halophilic strategies and transfer these characters into crop plants $[10,78]$. We have explained the possible ways (Fig. 2) to transform microbial information either directly into elite crop plants or after validation in relatively easy system (Arabidopsis thaliana) than that of a complex crop system that passes through various stages of the life cycle (i.e., from seed germination to grain maturation). Use of eukaryotic expression vectors, especially integrative vectors and inducible promoters are desired to make a robust and viable transformation, without adversely disturbing or limiting the photosynthesis and growth of the transformants. Here, we will discuss the outcome of some of the attempts made in this direction.

A freshwater cyanobacterium Synechococcus PCC 7942 transformed by a shuttle plasmid encoding Escherichia coli bet genes, synthesized GB resulting in stabilisation of photosynthetic activities and protection against salt stress [50]. Transformed Arabidopsis with methyl transferases genes from $A p$. halophytica showed enhanced salt tolerance [79]. The transformed Arabidopsis accumulated high level of GB in roots, stems, leaves and flow- ers, with improved seed yield under salt stress. Moreover, osmolytes like GB in addition to salinity confer resistance against other abiotic stresses [80]. However, not much are known about the molecular mechanism(s) of the protective effects of GB against other abiotic stresses. The protective effects of GB on the reproductive organs of plants have been observed in Arabidopsis, maize and tomato. Such protection might have involved high levels of GB that accumulate in the reproductive organs as a result of the translocation of GB from other organs, such as leaves [80]. Transformation of freshwater cyanobacterium $A$. doliolum with GB synthesizing genes (ApGSMT-DMT, glycine methylation genes) from Ap. halophytica boosted the salt tolerance of the transformants, but changed its behavior from freshwater to halophily [55]. Since use of the GSMT$D M T$ genes will have no adverse effect on our aim to develop salt tolerant crops, the behavioral shift could provide an insight into the evolution of saline life.

Our success in this direction will allow expansion of crops into salt affected environments, enabling increased food and fuel production to support the growing global population. Additional benefits may include lessening the burden of using freshwater for rearing crops. However, this will require concerted effort in elucidating the salt tolerance mechanism and engineering the biological structure(s) in plants.

\section{CONCLUSION}

Famous orthopedic surgeon Dr. Chitranjan Ranawat once said, "The eyes only see what the mind knows." Salt tolerance of crop plants could be improved by genetic engineering if we know the basic mechanisms of salt toxicity and defense responses at molecular level. Genetic engineering of crucial components of defense machinery and cellular targets of salt stress in high-salt inhabiting microbes could provide an insight into the salt tolerance that needs to be exploited. Since stress responses are conserved during evolution, information obtained with model microbial system could be employed to higher plants. Amongst microbes, microalgae and cyanobacteria are considered as better microbial systems as a proxy for crop plants. A protocol to transfer prokaryotic genes into multicellular eukaryotic systems has already been developed. Nonetheless, till date, no attempt has been made to transform crop plants using potential genes from these microbial systems. Furthermore, the recent exciting and growing field of research has presented 
that plants can remember the past stress events and prime their responses to react rapid and strong way to the coming bigger stress. The mechanisms include epigenetic regulation, transcriptional and protein priming. A mild salt stress for specific time period may prepare the organism for an improved response to higher salinity.

Acknowledgements: A.K. Rai gratefully acknowledges the National Academy of Sciences, India, for awarding NASI-Senior Scientist fellowship.

\section{REFERENCES}

1. Whyte RO (1961) Evolution of land use in SouthWestern Asia. In: Stamp LD (ed) A History of Land Use in Arid Regions, UNESCO, Paris, France, pp 57-118.

2. Epstein E, Bloom AJ (2005) Mineral Nutrition of Plants: Principles and Perspectives, 2nd edn, Sinauer Associates, Sunderland, MA, USA.

3. Jacobsen T, Adams RM (1958) Salt and silt in ancient Mesopotamian agriculture: Progressive changes in soil salinity and sedimentation contributed to the breakup of past civilizations. Science 128, 1251-1258.

4. Taylor AC (1965) Water, history and the Indus Plain. Nat Hist 24, 40-49.

5. Armillas P (1961) Land use in pre-Columbian America. In: Stamp LD (ed) A History of Land Use in Arid Regions, UNESCO, Paris, France, pp 255-276.

6. Tanji KK (1990) Nature and extent of agricultural salinity. In: Tanji KK (ed) Agricultural Salinity Assessment and Management, ASCE Manual 71, Amer Soc Civil Engrs, New York, USA, pp 1-17.

7. Rengasamy P (2006) World salinization with emphasis on Australia. J Exp Bot 57, 1017-1023.

8. Beresford Q, Bekle H, Phillips H, Mulcock J (2001) The Salinity Crisis: Landscapes, Communities and Politics, UWA Press, Perth, Australia.

9. Amini S, Ghadiri H, Chen C, Marschner P (2016) Salt-affected soils, reclamation, carbon dynamics, and biochar: A review. $J$ Soils Sediments 16, 939-953.

10. Zhu JK (2002) Salt and drought stress signal transduction in plants. Annu Rev Plant Biol 53, 247-273.

11. Hallsworth JE, Yakimov MM, Golyshin PN, Gillion JLM, D'Auria G, de Lima Alves F, La Cono V, Genovese $\mathrm{M}$, et al (2007) Limits of life in $\mathrm{MgCl}_{2}$-containing environments: Chaotropicity defines the window. Environ Microbiol 9, 801-813.

12. Oren A (2011) Thermodynamic limits to microbial life at high salt concentrations. Environ Microbiol 13, 1908-1923.

13. Grant WD, Gemmel RT, McGenity TJ (1998) Halophiles. In: Horikoshi K, Grant WD (eds) Extremophiles: Microbial Life in Extreme Environments, Wiley-Liss Inc., pp 93-132.
14. Hagemann M (2011) Molecualr biology of cyanobacterial salt acclimation. FEMS Microbiol Rev 35, 87-123.

15. Attri P, Venkatesu P, Lee M (2010) Influence of osmolytes and denaturants on the structure and enzyme activity of $\alpha$-chymotrypsin. $J$ Phys Chem 114, 1471-1478.

16. Ellis RJ, Hartl FU (1999) Principles of protein folding in the cellular environment. Curr Opin Struct Biol 9, 102-110.

17. Madern D, Ebel C, Zaccai G (2000) Halophilic adaptation of enzymes. Extremophiles 4, 91-98.

18. Wiggins PM (1990) Role of water in some biological processes. Microbiol Rev 54, 432-449.

19. Allakhverdiev SI, Kinoshita M, Inaba M, Suzuki I, Murata N (2001) Unsaturated fatty acids in membrane lipids protect the photosynthetic machinery against salt-induced damage in Synechococcus. Plant Physiol 125, 1842-1853.

20. Allakhverdiev SI, Murata N (2008) Salt stress inhibits photosystems II and I in cyanobacteria. Photosynth Res 98, 529-539.

21. Los DA, Zorina A, Sinetova M, Kryazhov S, Mironov K, Zinchenko VV (2010) Stress sensors and signal transducers in cyanobacteria. Sensors $\mathbf{1 0}$, 2386-2416.

22. Kaneko T, Nakamura Y, Sasamoto S, Watanabe A, Kohara M, Matsumoto M, Shimpo S, Yamada M, et al (2003) Structural analysis of four large plasmids harboring in a unicellular cyanobacterium Synechocystis sp. PCC 6803. DNA Res 10, 21-28.

23. Marin K, Suzuki I, Yamaguchi K, Ribbeck K, Yamamoto H, Kanesaki Y, Hagemann M, Murata N (2003) Identification of histidine kinases that act as sensors in the perception of salt stress in Synechocystis sp. PCC 6803. Proc Natl Acad Sci USA 100, 9061-9066.

24. Kanesaki Y, Yamamoto $H$, Paithoonrangsarid $K$, Shoumskaya M, Suzuki I, Hayashi H, Murata N (2007) Histidine kinases play important roles in the perception and signal transduction of hydrogen peroxide in the cyanobacterium, Synechocystis sp. PCC 6803. Plant J 49 313-324.

25. Mikami K, Kanesaki Y, Suzuki I, Murata N (2003) The histidine kinase Hik33 perceives osmotic stress and cold stress in Synechocystis sp. PCC6803. Mol Microbiol 46, 905-915.

26. Los DA, Murata N (2004) Membrane fluidity and its roles in the perception of environmental signals. Biochim Biophys Acta 1666, 142-157.

27. Torrecilla I, Leganes F, Bonilla I, Fernandez-Pinas F (2001) Calcium transients in response to salinity and osmotic stress in the nitrogen-fixing cyanobacterium Anabaena sp. PCC7120, expressing cytosolic apoaequorin. Plant Cell Environ 24, 641-648.

28. Lobanova KV, Kerbalaeva AM, Tashpulatov ZZ, Gulyamova TG (2008) Carotene-forming activity of 
certain halophilic bacteria from Barsakelmes saline soil. Chem Nat Compd 44, 306-307.

29. Fendrihan S, Legat A, Pfaffenhuemer M, Gruber C, Weidler G, Gerbl F, Stan-Lotter H (2006) Extremely halophilic archaea and the issue of long-term microbial survival. Rev Environ Sci Biotechnol 5, 203-218.

30. Roeßler M, Müller V (1998) Quantitative and physiological analyses of chloride dependence of growth of Halobacillus halophilus. Appl Environ Microbiol 64, 3813-3817.

31. Epstein W (2003) The roles and regulation of potassium in bacteria. Prog Nucleic Acid Res Mol Biol 75, 293-320.

32. Saum SH, Müller V (2008) Regulation of osmoadaptation in the moderate halophile Halobacillus halophilus: chloride, glutamate and switching osmolyte strategies. Saline System 4, ID 4.

33. Shono M, Hara Y, Wada M, Fujii TA (1996) A sodium pump in the plasma membrane of the marine alga Heterosigma akashiwo. Plant Cell Physiol 37, 385-388.

34. Morth JP, Pedersen BP, Buch-Pedersen MJ, Andersen JP, Vilsen B, Palmgren MG, Nissen P (2011) A structural overview of the plasma membrane $\mathrm{Na}^{+}, \mathrm{K}^{+}$ATPase and $\mathrm{H}^{+}$-ATPase ion pumps. Nat Rev Mol Cell Biol 12, 60-70.

35. Soontharapirakkul K, Promden W, Yamada N, Kageyama H, Incharoensakdi A, Iwamoto-Kihara A, Takabe T (2011) Halotolerant cyanobacterium Aphanothece halophytica contains a $\mathrm{Na}^{+}$-dependent $\mathrm{F}_{1} \mathrm{~F}_{0}$-ATP synthase with potential role in salt-stress tolerance. J Biol Chem 286, 10169-10176.

36. Waditee R, Hibino $T$, Nakamura $T$, Incharoensakdi A, Takabe $\mathrm{T}$ (2002) Overexpression of a $\mathrm{Na}^{+} / \mathrm{H}^{+}$ antiporter confers salt tolerance on a freshwater cyanobacterium, making it capable of growth in sea water. Proc Natl Acad Sci USA 99, 4109-4114.

37. Klähn S, Hagemann M (2011) Compatible solute biosynthesis in cyanobacteria. Environ Microbiol 13, 551-562.

38. Warr SRC, Reed RH, Stewart WDP (1987) Lowmolecular-weight carbohydrate biosynthesis and the distribution of cyanobacteria (blue-green algae) in marine environments. Eur J Phycol 22, 175-180.

39. Rontein D, Basset G, Hanson AD (2002) Metabolic engineering of osmoprotectant accumulation in plants. Metab Eng 4, 49-56.

40. Sukharev SI, Betanzos M, Chiang CS, Guy HR (2001) The gating mechanism of the large mechanosensitive channel MscL. Nature 409, 720-724.

41. Jeanjean R, Matthijs HCP, Onana B, Havaux M, Joset F (1993) Exposure of the cyanobacterium Synechocystis PCC6803 to salt stress induces concerted changes in respiration and photosynthesis. Plant Cell Physiol 34, 1073-1079.

42. Reddy PS, Pogoryelov D, Kovacs L, Garab G, Murthy SDS (2005) The effects of salt stress on photosyn- thetic electron transport and thylakoid membrane proteins in the cyanobacterium Spirulina platensis. BMB Rep 38, 481-485.

43. Rai AK, Abraham G (1993) Salinity tolerance and growth analysis of the cyanobacterium Anabaena doliolum. Bull Environ Contam Toxicol 51, 724-731.

44. Rai AK (1990) Biochemical characteristics of photosynthetic response to various salinities in halotolerant and freshwater cyanobacteria. FEMS Microbiol Lett 69, 177-180.

45. Lu C, Zhang J (2000) Role of light in the response of PSII photochemistry to salt stress in the cyanobacÂnterium Spirulina platensis. J Exp Bot 51, 911-917.

46. Swapnil P, Singh M, Singh S, Sharma NK, Rai AK (2015) Recombinant glycinebetaine improves metabolic activities, ionic balance and salt tolerance in diazotrophic freshwater cyanobacteria. Algal Res 11, 194-203.

47. Hibino T, Lee BH, Rai AK, Ishikawa $H$, Kojima $H$, Tawada M, Shimoyama H, Takabe T (1996) Salt enhances photosystem I content and cyclic electron flow via $\mathrm{NAD}(\mathrm{P}) \mathrm{H}$ dehydrogenase in the halotolerant cyanobacterium Aphanothece halophytica. Aust $J$ Plant Physiol 23, 321-330.

48. Flameling IA, Kromkamp J (1994) Responses of respiration and photosynthesis of Scenedesmus protuberans Fritsch to gradual and steep salinity increases. $J$ Plankton Res 16, 1781-1791.

49. Moisander PH, McClinton E, Paerl H (2002) Salinity effects on growth, photosynthetic parameters, and nitrogenase activity in estuarine planktonic cyanobacteria. Microb Ecol 43, 432-442.

50. Nomura M, Ishitani M, Takabe T, Rai AK, Takabe T (1995) Synechococcus sp. PCC 7942 transformed with Escherichia coli Bet genes produces betaine from choline and acquires resistance to salt stress. Plant Physiol 107, 703-708.

51. Gabbay-Azaria R, Sehonfeld M, Tel-Or S, Messinger $\mathrm{R}$, Tel-Or E (1992) Respiratory activity in the marine cyanobacterium Spirulina subsalsa and its role in salt tolerance. Arch Microbiol 157, 183-190.

52. Rai AK, Tiwari SP (1999) Response to $\mathrm{NaCl}$ of nitrate assimilation and nitrogenase activity of the cyanobacterium Anabaena sp. PCC 7120 and its mutants. J Appl Microbiol 87, 877-833.

53. Deits TL, Howard JB (1990) Effect of salts on Azotobacter vinelandii nitrogenase activities. Inhibition of iron chelation and substrate reduction. $J$ Biol Chem 265, 3859-3867.

54. Blumwald E, Mehlhorn RJ, Packer L (1983) Ionic osmoregulation during salt adaptation of the cyanobacterium Synechococcus 6311. Plant Physiol 73, 377-380.

55. Singh M, Sharma NK, Prasad SB, Yadav SS, Narayan G, Rai AK (2013) The freshwater cyanobacterium Anabaena doliolum transformed with ApGSMT-DMT exhibited enhanced salt tolerance and protection to 
nitrogenase activity, but became halophilic. Microbiology 159, 641-648.

56. Rai AK, Abraham G (1995) Relationship of combined nitrogen sources to salt tolerance in freshwater cyanobacterium Anabaena doliolum. J Appl Bacteriol 70, 501-506.

57. Rai AK, Tiwari SP (1999b) $\mathrm{NO}_{3}^{-}$nutrition and salt tolerance in the cyanobacterium Anabaena sp. PCC 7120 and mutant strains. J Appl Microbiol 86, 991-998.

58. Neto MCL, Lobo AKM, Martins MO, Fontenele AV, Silveira JAG (2014) Dissipation of excess photosynthetic energy contributes to salinity tolerance: a comparative study of salt-tolerant Ricinus communis and salt-sensitive Jatropha curcas. J Plant Physiol 171, 23-30.

59. White AK, Metcalf WW (2007) Microbial metabolism of reduced phosphorus compounds. Annu Rev Microbiol 61, 379-400.

60. Rai AK, Sharma NK (2006) Phosphate metabolism in the cyanobacterium Anabaena doliolum under salt stress. Curr Microbiol 52, 6-12.

61. Kageyama H, Tripathi K, Rai AK, Cha-um S, WaditeeSirisattha R, Takabe T (2011) An alkaline phosphatase/phosphodiesterase, PhoD, induced by salt stress and secreted out of the cells of Aphanothece halophytica, a halotolerant cyanobacterium. Appl Environ Microbiol 77, 5178-5183.

62. Tripathi K, Sharma NK, Kageyama H, Takabe T, Rai AK (2013) Physiological, biochemical and molecular responses of the halophilic cyanobacterium Aphanothece halophytica to Pi-deficiency. Eur J Phycol 48, 461-473.

63. Foyer C, Noctor G, Buchanan B, Dietz K, Pfannschmidt T (2009) Redox regulation in photosynthetic organisms: signaling, acclimation, and practical implications. Antioxid Redox Signal 11, 861-905.

64. Swapnil P, Yadav AK, Srivastav S, Sharma NK, Srikrishna S, Rai AK (2017) Biphasic ROS accumulation and programmed cell death in a cyanobacterium exposed to salinity $\left(\mathrm{NaCl}\right.$ and $\mathrm{Na}_{2} \mathrm{SO}_{4}$ ). Algal Res 23, 88-95.

65. Sagi M, Fluhr R (2006) Production of reactive oxygen species by plant NADPH oxidases. Plant Physiol 141, 336-340.

66. Ma L, Zhang H, Sun L, Jiao Y, Zhang G, Miao C, Hao F (2012) NADPH oxidase AtrbohD and AtrbohF function in ROS-dependent regulation of $\mathrm{Na}^{+} / \mathrm{K}^{+}$ homeostasis in Arabidopsis under salt stress. $J$ Exp Bot 63, 305-317.

67. Santana-Sanchez A, Solymosi D, Mustila, H, Bersanini L, Aro EM, Allahverdiyeva Y (2019) Flavodiiron proteins 1-to-4 function in versatile combinations in $\mathrm{O}_{2}$ photoreduction in cyanobacteria. Elife 8, e45766.

68. Zheng W, Rasmussen U, Zheng S, Bao X, Chen B, Gao Y, Guan X, Larsson J, et al (2013) Multiple modes of cell death discovered in a prokaryotic (cyanobacterial) endosymbiont. PLoS One 8, e66147.

69. Datt JF, Pellinen R, Beeckman T, Van De Cotte B, Langebartels C, Kangasjervi J, Inzé D, Van Breusegem F (2003) Changes in hydrogen peroxide homeostasis trigger an active cell death process in tobacco. Plant $J$ 33, 621-632.

70. Berman-Frank I, Bidle KD, Haramaty L, Falkowski PG (2004) The demise of the marine cyanobacterium, Trichodesmium spp., via an autocatalyzed cell death pathway. Limnol Oceanogr 49, 997-1005.

71. Rai AK, Pandey KD, Kashyap AK (1978) Heterocyst differentiation and polarity in Calothrix. New Phytol 81, 647-651.

72. Swapnil P, Rai AK (2018) Physiological responses to salt stress of salt-adapted and directly salt $(\mathrm{NaCl}$ and $\mathrm{NaCl}+\mathrm{Na}_{2} \mathrm{SO}_{4}$ mixture)-stressed cyanobacterium Anabaena fertilissima. Protoplasma 255, 963-976.

73. Rai AK, Swapnil P (2019) Proteomic analysis of the salt-adapted and directly salt- $(\mathrm{NaCl}$ and $\mathrm{NaCl}+\mathrm{Na}_{2} \mathrm{SO}_{4}$ mixture) stressed cyanobacterium $\mathrm{An}$ abaena fertilissima. J Appl Phycol 31, 1185-1196.

74. Rai V, Rai AK (1999) Growth behaviour of Azolla pinnata at various salinity levels and induction of high salt tolerance. Plant Soil 206, 79-84.

75. Mauch-Mani B, Baccelli I, Luna E, Flors V (2017) Defense priming: an adaptive part of induced resistance. Annu Rev Plant Biol 68, 485-512.

76. Bacova R, Kolackova M, Klejdus B, Adam V, Huska D (2020) Epigenetic mechanisms leading to genetic flexibility during abiotic stress responses in microalgae: A review. Algal Res 50, ID 101999.

77. Bhatnagar-Mathur P, Palit P, Sharma KK (2014) Horizontal gene transfer through genetic transformation. In: Pratap A, Kumar J (eds) Alien Gene Transfer in Crop Plants, vol 1, Springer, New York, USA, pp 105-141.

78. Yamaguchi T, Blumwald E (2005) Developing salttolerant crop plants: challenges and opportunities. Trends Plant Sci 10, 615-620.

79. Waditee R, Bhuiyan MH, Rai V, Aoki K, Tanaka Y, Hibino T, Suzuki S, Takano J, et al (2005) Genes for direct methylation of glycine provide high levels of glycinebetaine and abiotic-stress tolerance in Synechococcus and Arabidopsis. Proc Natl Acad Sci USA 102, 1318-1323.

80. Chen THH, Murata N (2011) Glycinebetaine protects plants against abiotic stress: mechanisms and biotechnological applications. Plant Cell Environ 34, $1-20$. 